\title{
Large gastric intramural hematoma: unusual complication of endoscopic submucosal dissection
}

A 72-year-old woman was referred for evaluation of a gastric subepithelial tumor ( $\bullet$ Fig. 1). The patient had no remarkable medical history. Laboratory evaluation revealed normal platelet count and coagulation profiles. Following discussion with the patient, diagnostic endoscopic submucosal dissection (ESD) was carried out. The procedure was initiated with a submucosal saline injection using a 23-G injection needle (NM-200L-0423, Olympus, Tokyo, Japan) to raise the lesion. Soon after the injection, the patient experienced epigastric pain and the formation of a hematoma, which progressively enlarged over the injection site ( $\mathbf{F i g}$. 2). The patient was admitted and received conservative treatment including blood transfusion, fasting, a proton pump inhibitor (esomeprazole), and pain control using tramadol. Follow-up endoscopic examination on day 6 revealed an enormous ulcer in the area of the injection site ( $\bullet$ Fig. 3). Oral feeding was recommenced and the patient was discharged. Followup endoscopy after 3 months revealed complete healing of the ulcer with some scarring ( $\bullet$ Fig. 4).

Previous reports regarding the causes of gastric hematoma have referred mainly to coagulopathy; other reported cases were caused by aneurysms, peptic ulcers, spontaneous hematomas, pancreatitis, and percutaneous endoscopic gastrostomy [1 - 3]. Symptoms of gastric hematoma are hematemesis, the passage of melena, chest pain, and epigastric discomfort. The management of gastric intramural hematomas depends on the clinical situation. Surgery is reserved for recurrent gastric hemorrhaging or perforation of the hematoma into the peritoneal cavity. In the present case, we believe that the gastric intramural hematoma was caused by trauma to the blood vessels during the submucosal injection. Although this is the first case report of a gastric intramural hematoma associated with ESD, we recommend that endoscopists should be wary of this potential complication when carrying out ESD for subepithelial tumors.

Endoscopy_UCTN_Code_CPL_1AH_2AZ

\section{Competing interests: None}

\section{W. Yang, H. H. Yen}

Department of Gastroenterology, Changhua Christian Medical Center,

Changhua, Taiwan

\section{References}

1 Dhawan V, Mohamed A, Fedorak RN. Gastric intramural hematoma: A case report and literature review. Can J Gastroenterol 2009; 23: $19-22$

2 Jowett S, Midwinter M, Tapson J et al. Gastric wall haematoma as a complication of percutaneous endoscopic gastrostomy insertion. Endoscopy 1999; 31: S48

3 Chou CT, Chen RC, Yang AD. Gastric subserosal hematoma developing from focal pancreatitis: a case report. Kaohsiung J Med Sci 2009; 25 : $45-48$

\section{Bibliography}

DOI $10.1055 / \mathrm{s}-0030-1256521$

Endoscopy 2011; 43: E240

(c) Georg Thieme Verlag KG Stuttgart · New York . ISSN 0013-726X

\section{Corresponding author \\ H. H. Yen}

Department of Gastroenterology

Changhua Christian Medical Center

Changhua

Taiwan

Fax: +886-7-7228289

91646@cch.org.tw

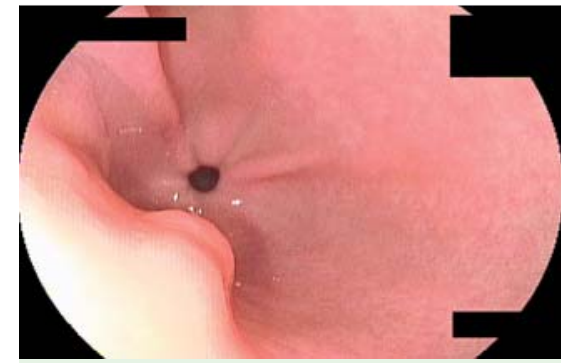

Fig. 1 Endoscopic view of the subepithelial tumor in the antrum.

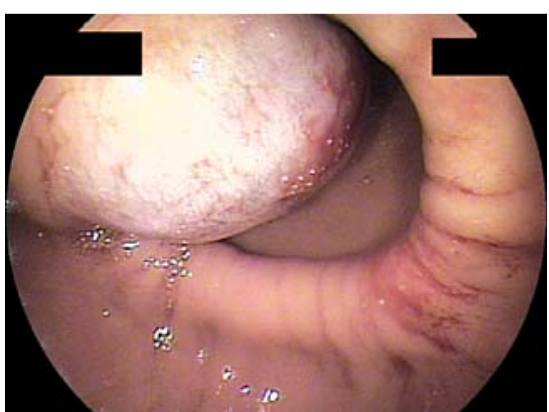

Fig. 2 Formation of large gastric intramura hematoma following submucosal saline injection.

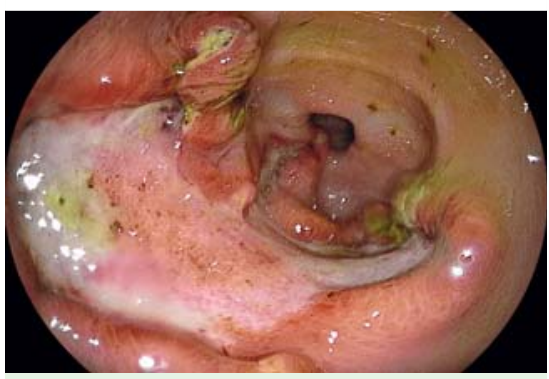

Fig. 3 Endoscopic view of the enormous gastric ulcer in place of the intramural hematoma after 5 days of conservative treatment.

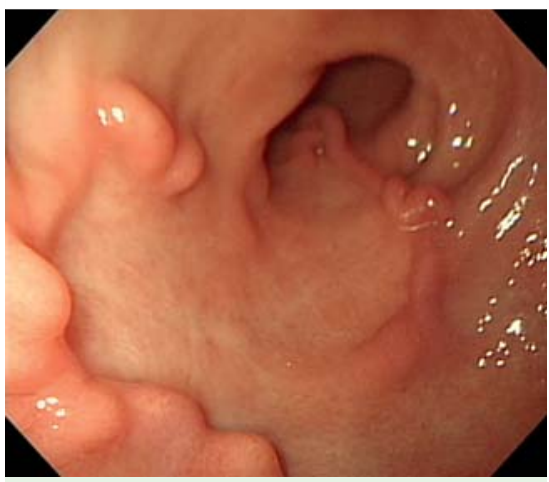

Fig. 4 Endoscopic examination 3 months later showing gastric scar. 